Localization Economies and Firm Productivity: Evidence from Football Teams in Sao Paulo, Brazil

Brad Humphreys

Amir B. Neto

Follow this and additional works at: https://researchrepository.wvu.edu/econ_working-papers

Part of the Regional Economics Commons, Sports Studies Commons, and the Urban Studies and Planning Commons 


\title{
Localization Economies and Firm Productivity: Evidence from Football Teams in São Paulo, Brazil
}

\author{
Brad R. Humphreys* \\ West Virginia University \\ Amir B. Ferreira Neto ${ }^{\dagger}$ \\ Florida Gulf Coast University
}

July 2020

\begin{abstract}
Agglomeration economies affect urban economic outcomes. We analyze variation in sports team productivity and localization of teams across divisions and cities in Campeonato Paulista an annual football competition in São Paulo state, Brazil, exploiting plausibly exogenous variation in localization generated by a promotion and relegation system in this league. Results show that both urbanization, proxied by population, and localization affects short and long run team productivity. These results provide new evidence on the importance of localization economies in the urban economy in developing countries and shed light on why sports teams in larger cities enjoy more success than those in smaller cities.
\end{abstract}

Keywords: Agglomeration, urbanization, localization, sports league outcomes, Elo rankings

JEL Classification: R12, Z21

${ }^{*}$ Department of Economics, Chambers College of Business and Economics, 1601 University Ave., PO Box 6025, Morgantown, WV 26506-6025, USA; Email: brad.humphreys@mail.wvu.edu. We thank seminar participants at Clemson University, West Virginia University, the 2018 Midwest Graduate Student Summit on Applied Economics, Regional and Urban Studies (AERUS) Conference, and the 2018 Eastern Economic Association Conference for valuable comments and suggestions.

${ }^{\dagger}$ Lutgert College of Business, 10501 FGCU Blvd. S., Fort Myers, FL 33965; Email: aborgesferreiraneto@fgcu.edu 


\section{Introduction}

Agglomeration economies clearly affect urban economic outcomes. Firms in specific industries tend to cluster together and economic activity tends to cluster in specific areas. Urban firms are more productive because of the spatial concentration of other firms in their industry and because of the urban spatial concentration of general economic activity and population. Agglomeration economies represent especially important urban phenomena in developing countries Glaeser and Xiong (2017). A large body of empirical evidence shows that both localization economies and urbanization economies affect firms in cities.

Economists recognized the importance of agglomeration economies as far back as the 19th century. Firms that locate close to each other enjoy localization economies from several sources including sharing of intermediate inputs, job-market pooling and matching, and knowledge spillovers. Glaeser et al. (1992) developed the MAR [Marshall (1895) - Arrow (1962) - Romer (1986)] model to explain localization from knowledge spillovers.

Urbanization economies (Jacobs, 1969) represent another important benefit of agglomeration. Jacob's argument differs from the MAR approach in that diversification represents a key ingredient to foster innovation and growth. Moreover, Jacobs (1969) argued that urban scale, in terms of the density and level of local demand and population, also affects firms. A large empirical literature examines the impact of localization and urbanization economies (Moomaw, 1988; Henderson, 2003; Viladecans-Marsal, 2004; Duranton and Overman, 2005; Devereux et al., 2007; Groot et al., 2014; Galliano et al., 2015), but reaches no conclusive answer in terms of which effect dominates, or how strong an influence either provides.

Urbanization economies clearly play an important role in the performance of teams in professional sports leagues. The standard textbook economic model of sports league outcomes emphasizes that teams play in home markets (cities) of different sizes, and that team productivity increases with the size of the home market (Fort and Quirk, 1995). This model predicts that teams in larger cities will be more successful than teams in smaller cities; a large body of empirical research confirms this prediction. 
Interestingly, the existing literature on outcomes in professional sports largely ignored localization economies until recently. Standard models of sports league outcomes do not address clustering of teams in cities or assess any impact this might have on outcomes like team success. This appears to be a curious omission, since sports teams clearly cluster in large cities. Three MSAs in the US ${ }^{1}$ - New York, Los Angeles and Chicago - have more than five professional football, basketball, baseball and hockey teams and another 10 MSAs have four. The greater London metro area currently has 12 teams playing in the top two football leagues in the UK and a large number of top-level football teams in the German Bundesliga are concentrated in the Rhein-Ruhr region.

The literature on sport and localization is thin and recent. Most of this literature focuses on broadcast viewership or team pricing decisions. Mills et al. (2016) and Mondello et al. (2017) discussed how shared markets impact broadcast viewership in Major League Baseball (MLB) and the National Football League (NFL) and reported evidence supporting localization effects in professional baseball broadcasts and evidence of local media cannibalization in professional football broadcasts. Driessen and Sheffrin (2017) analyzed how industry concentration impacts location decisions for race car drivers and golfers, finding that tax preferences are an important determinant of clustering for golfers, but agglomeration reduces this effect on the location of race car drivers, who tend to cluster in a small area in North Carolina. Henrickson (2012) analyzed pricing decisions made by professional sports teams in US cities and finds evidence of spatial competition in pricing. None of these papers analyze the impact of localization on team productivity.

Two recent papers analyze the relationship between proximity of sports teams and team performance in developed countries. Doran and Jordan (2018) analyze the impact of the success of other nearby football teams on own football team performance in England over the period 1992-2012 using a spatial econometric approach. Doran and Jordan (2018) find that proximity to other high preforming teams improves team performance and suggest that

\footnotetext{
${ }^{1}$ From a North American perspective, one can also think about minor leagues in baseball and ice hockey that concentrate in specific regions.
} 
agglomeration drives this effect. Jones and Jordan (2019) examine the relationship between urbanization and football team success in England over the period 1992-2012. Jones and Jordan (2019) show that teams playing in conurbations with larger populations finished higher in the football standings across the top four football leagues in England.

Identifying how localization influences team outcomes requires variation in the concentration of teams in cities over time. Team relocation to another city represents one way to generate such variation, but relocation of teams is a rare event in US leagues and almost nonexistent elsewhere. However, unlike professional sports leagues in the US, football leagues in Europe and South America use a promotion-relegation system which generates variation in the degree of localization of teams in different leagues or divisions as teams are promoted and relegated at the end of every season. ${ }^{2}$

We analyze the relationship between variation in team productivity and the localization of teams across divisions and cities in Campeonato Paulista (CP), an annual football competition played by teams in São Paulo state in Brazil. São Paulo state represents an interesting setting for the analysis of localization and team sports outcomes. Brazil is a developing country, and relatively little empirical research focuses on urbanization and localization in developing countries Glaeser and Xiong (2017). With roughly the same area as the United Kingdom $\left(248,222 \mathrm{~km}^{2}\right.$ versus $\left.243,610 \mathrm{~km}^{2}\right)$ and roughly the same population as Spain $(45,149,486$ versus $46,347,576)$, São Paulo state contains substantial variability in population and area across sub-state geographic units. São Paulo state contains three cities with a population of more than one million (including São Paulo with a population of 11 million) and another six cities with population of more than 500,000.

Campeonato Paulista represents an interesting setting for this analysis because of its promotion and relegation structure that generates year-to-year variation in localization, and also because of several institutional features that help mitigate some possible empirical problems.

\footnotetext{
${ }^{2}$ In all parts of the world except the US and Canada, the immensely popular eleven player ball and goal sport is called football. In the US and Canada, this sport is called soccer. In keeping with the worldwide convention, we refer to this sport as football throughout this paper.
} 
For instance, the CP competition occurs over the January through May period, which does not coincide with the primary football hiring season in Europe (June-September) leading to stability in team rosters not present in other leagues.

Because it is a regional league, teams occasionally hire international players, but most of the CP players will be from within Brazil. This would be a bigger issue in the case of developed countries in Europe where players have free movement across European Union member countries and often move mid-season. São Paulo has the oldest state football competition in Brazil and is the wealthiest state in the country. Also, Brazilian football teams almost never move, mitigating any potential firm selection effects that plague other empirical research on agglomeration and firm productivity (Doran and Jordan, 2018; Jones and Jordan, 2019).

We collect data on Campeonato Paulista team outcomes from the 2007 to 2018 seasons. We analyze both short-term and long-term team outcomes. Short-term outcomes occur within a single season in each CP division and consist of: win-loss ratio, goal differential in terms of goals scored minus goals allowed, and total points accrued in each season. The long-term outcome consists of a novel Elo score reflecting team performance relative to expectations we develop in this paper. The underlying mechanisms through which localization and urbanization affect firm performance remain elusive. Analyzing short and long term performance helps shed light on how these mechanisms work.

We calculate three alternative measures of team concentration in each municipality to proxy for localization: a count of teams in each municipality in each division-season, the raw concentration index developed by Ellison and Glaeser $(1994,1997)$ (EGI), and the raw concentration measure developed by Maurel and Sédillot (1999) (MSI). We proxy for urbanization economies using population and municipality-level median wage. We also collect data on time-varying characteristics of municipalities such as employment and value added in production by industry. Municipalities are the smallest administrative divisions in Brazil with autonomous local government comprising of an executive and legislative branches.

Our results show that both localization and urbanization externalities explain football 
team's short-run and long-run success. Urbanization as proxied by municipality population, increases local football team success, as predicted by the theoretical model. The results also support the importance of localization economies, but the direction of the impact of localization on team success differs systematically by division of play. These differences can be explained by labor market pooling and matching, as well as the zero-sum nature of within-division outcomes in football leagues.

This paper makes several contributions to the literature. We develop evidence that localization and urbanization affect firm productivity in cities in a developing country. We exploit a unique institutional characteristic, promotion and relegation, to generate exogenous variation in the level of industry localization in each city. Most previous empirical research on localization lacks high frequency exogenous variation in localization proxy variables, making this empirical approach of interest in empirical urban economics. We also analyze both short run and long run firm productivity, proxied by team success, and find that localization and urbanization affect both short run and long run firm productivity. While the result that agglomeration effects work at both time horizons my be unsurprising, empirical evidence confirming this represents a contribution.

This is the first paper, to our knowledge, to theoretically and empirically demonstrate the importance of localization economies in sports leagues. Previous research focused only on the role of urbanization or proximity to other teams. We show that changes in the number of other teams in the same municipality across seasons has an important impact on a team's short and long run level of success. Not only the presence of more teams plays a role in the success of other teams, but also the quality of the "neighboring" teams. This expands our understanding of large market/small market disparities in professional sports leagues. 


\section{A Model of League Outcomes with Agglomeration}

Firms gain both internal and external benefits from locating in cities, compared to firms located outside cities (Quigley, 1998). Internal benefits include scale economies or indivisibilities within firms that can only be exploited by growing large, shared inputs in production with other co-located firms, reductions in transaction costs from better matching between firms and employees, and related decreases in search costs. External benefits stem from city size, typically called urbanization externalities, or from the presence of other similar firms, called localization externalities. Rosenthal and Strange (2004) found that doubling urban size increased firm productivity by about $5 \%$, a substantial benefit from urbanization. While a large number of studies confirm the importance of localization externalities in a different industries, no previous research analyzes localization in terms of firms in the sports industry.

In order to understand the effect of localization on outcomes in sports leagues, we extend the standard "two team" model of sports league outcomes (Fort and Quirk, 1995) to include localization economies. In this model, teams produce wins using playing talent and managerial talent and sell these wins to fans. Since teams in sports leagues jointly produce wins, including localization economies in a model of a sports league represents an important component of this paper, because other economic models of urban outcomes do not include this feature. For simplicity, the model includes only two teams, identified by subscripts $i$ and $j$, although the results generalize in a straightforward way to the case of $N$ teams (El-Hodiri and Quirk, 1971; Fort and Quirk, 1995). Following the standard approach in the literature, assume that team $i$ plays in a large city characterized by strong urbanization and localization effects and team $j$ plays in a small city with weak effects.

Both teams maximize profits by choosing their level of success, proxied by team winning percentage $(W)$. Teams' revenues depend on team success $W$ and the team's market revenue generating potential $(M)$. The team's market revenue generating potential $(M)$ is assumed to be a function of both urbanization $(u)$ and localization externalities $(a)$ that differ across each city. $M_{i}\left(u_{i}, a_{i}\right)>M_{j}\left(u_{j}, a_{j}\right)$ by assumption, because team $i$ plays in a large city. The 
urbanization and localization economies (or externalities) should have a positive effect on each team's market revenue generating potential. For instance, large and more dense cities would create a larger market for the team to sell wins in. Also, urban areas have higher median wages (Glaeser and Maré, 2001; Glaeser, 1998; Glaeser et al., 2001) which should positively impact $M$.

The overall impact of localization externalities on $M$ cannot be signed. For example, the presence of several teams in a city implies that the local market will be split between teams, which can reduce each team's individual market revenue potential. However, when more than one team plays in a city a rivalry between teams is likely to emerge. This rivalry could increase local market potential, as customers would become more passionate about their teams, increasing the importance of teams in consumers' utility functions (Szymanski, 2009). For example, numerous intense rivalries exist between football teams in London and Buenos Aires.

São Paulo features not only municipal level rivalries but also regional and state level rivalries. The municipality level rivalry stems from neighborhoods and even differences in supporter socio-demographic characteristics. At the regional level, these rivalries emerge from repeated interaction in state and national competitions. For example in São Paulo, municipality powerhouse teams like São Paulo, Palmeiras, and Corinthians have different historic backgrounds and fan identification; in Campinas, the two main teams once played in side-by-side private stadiums; at the state level, strong rivalries exist between powerhouse teams in São Paulo and Santos, a team located about 46mi from São Paulo that once counted Pelé on the roster.

Localization economies also work through labor market pooling and matching. These can also have differential impacts on team success. A city with many teams playing in lower divisions might offer teams playing in higher divisions an attractive source of new talent, increasing the success of teams playing in higher divisions and reducing the success of teams playing in lower divisions. On the other hand, in a city with a large number of teams playing 
in the top division, high productivity players on these teams who are not good enough to earn a starting position might be attractive players to teams playing in lower divisions. This would tend to reduce the success of teams playing in higher divisions and increase the success of teams playing in lower divisions in the city.

Teams' production costs include a fixed cost $\left(F_{i}\right)$ and the marginal cost of playing talent $(p)$, which can be interpreted as the average salary paid to homogenous players. If a team operates in an area with agglomeration economies, it should benefit from the most common sources of localization economies: shared intermediate inputs, labor market pooling and improved player-team matching, and knowledge spillovers. The variable $(a)$ reflects these factors, which are internal to teams but external to a team's "plant" or stadium. Localization economies should have an effect on the team's costs, in terms of either the marginal price of talent or fixed costs. Therefore, we can write each team $i$ 's objective function as

$$
\max _{W_{i}} \Pi_{i}=R_{i}\left(W_{i}, M_{i}\left(a_{i}, u_{i}\right)\right)-F_{i}-p_{i}\left(a_{i}\right) W_{i}
$$

and team $j$ 's objective function as

$$
\max _{W_{j}} \Pi_{j}=R_{j}\left(W_{j}, M_{j}\left(a_{j}, u_{j}\right)\right)-F_{j}-p_{j}\left(a_{j}\right) W_{j}
$$

where $a$ captures localization economies, $u$ captures urbanization economies, and $p(a)$ is the marginal cost of talent, which depends on localization. Localization economies imply that the marginal cost of talent is lower for the team playing in a dense urban area, so $p^{\prime}(a)<0$. $u$ captures the effect of urbanization economies, which, by assumption, affect revenues but not labor costs.

By definition, as both teams play in the same division, the "adding up constraint" holds; i.e., the sum of team winning percentages equals one. In addition, the equilibrium in this market occurs where the marginal revenue (MR) of team $i$ equals the marginal revenue of team $j$. 
We focus primarily on the relationship between the agglomeration economies (urbanization and localization) and team success. Thus, we can use the implicit function theorem and the first order conditions from profit maximization to obtain comparative statics between equilibrium winning percent and agglomeration. For simplicity, we assume that only team $i$ will enjoy agglomerative effects as a consequence of playing in a large city. Job market pooling and matching should make it easier for team $i$ to hire talent.

Moreover, the knowledge spillovers from informal non-market interaction between players and coaches should also increase the productivity of such players at any marginal price (Glaeser et al., 2000). Therefore, we expect a negative relationship between agglomeration and the marginal cost of playing talent. On the other hand, because team $j$ experiences no agglomeration economies, we should expect a constant marginal price for talent for this team.

Like in El-Hodiri and Quirk (1971) and Fort and Quirk (1995), we assume total team revenue to be strictly concave in $W$. We also assume revenue is strictly concave in $M$. Below, subscripts represent the partial derivatives. The relevant comparative static terms are

$$
\begin{gathered}
\frac{\partial W_{i}}{\partial a_{i}}=-\frac{\left(R_{W a} * M_{a}-p_{a}\right)}{R_{W W}} \gtrless 0 \\
\frac{\partial W_{j}}{\partial a_{j}}=-\frac{\left(R_{W a} * M_{a}-p_{a}\right)}{R_{W W}}=0 \\
\frac{\partial W_{i}}{\partial u_{i}}=-\frac{\left(R_{W u} * M_{u}\right)}{R_{W W}}>0 \\
\frac{\partial W_{j}}{\partial u_{j}}=-\frac{\left(R_{W u} * M_{u}\right)}{R_{W W}}=0 .
\end{gathered}
$$

The comparative statics generate clear predictions regarding the impact of urbanization economies on outcomes. In the presence of urbanization economies (equations 5 and 6) like 
those described by Jacobs (1969), the team playing in a large city has a higher equilibrium winning percent than the team playing in a smaller city. In equilibrium, teams playing in large cities will be more productive, and more successful, than teams playing in small cities. However, in terms of localization economies (equations 3 and 4), as described by Marshall (1895), we cannot clearly sign the relationship between the localization externality and market revenue potential. Our empirical analysis will help to shed some light in this issue.

The two team model features a graphical solution, in terms of the determination of equilibrium winning percentages in a league of two profit maximizing teams. Figure 1 shows the standard league equilibrium in the two team model, point $E_{1}$ with urbanization, reflected in the assumption that $M_{i}>M_{j}$ and no agglomeration effects on input prices $\left(p_{j}=p_{i}=p_{1}\right)$. In the graphical solution to the two team model, team $j$ 's success, $W_{j}$ is shown as increasing from left to right and team $i$ 's success is shown increasing from right to left. The adding up constraint means that any league outcome must occur on a vertical line in the $(W \times \$)$ space.

Figure 1: League Equilibrium With and Without Agglomeration

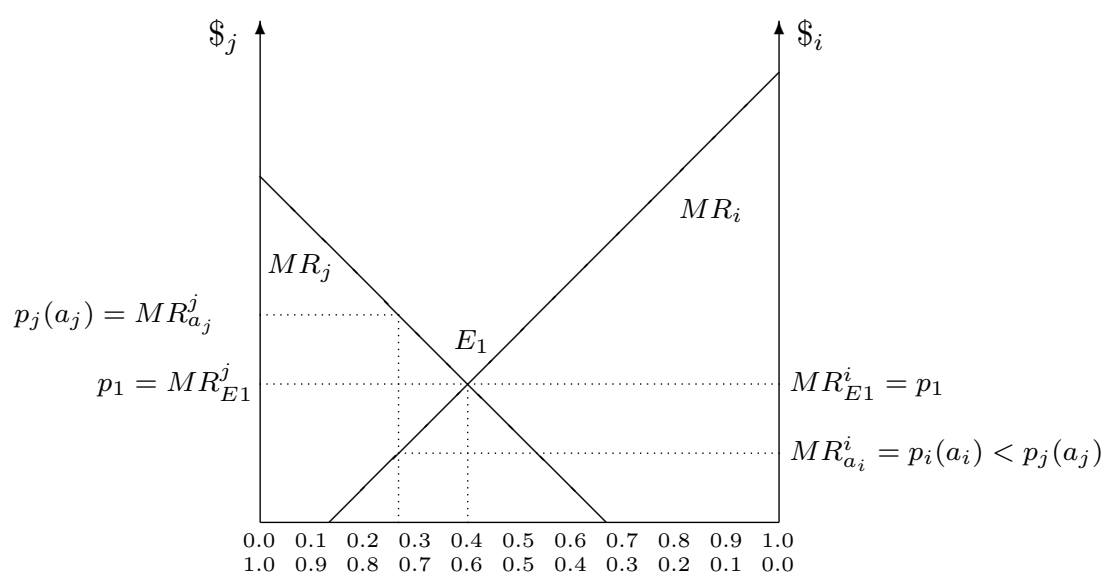

Team $i$ plays in a large city with larger urbanization externalities than team $j$, so team $i$ 's MR curve is higher than team $j$ 's MR curve. In equilibrium, both teams maximize profits 
and face the same price of talent. In equilibrium, $M R_{j}=M R_{i}=p_{1}$ so both teams maximize profits. However, because team $i$ enjoys the benefits of urbanization, and has more fans to sell wins to, and potentially a higher willingness to pay for wins due to higher urban wages, $W_{i}>W_{j}$ in equilibrium. The league equilibrium outcomes are unbalanced and team $i$ is more successful than team $j$ on average.

If agglomeration effects reduce the marginal cost of acquiring playing talent for team $i$, because of shared input pools and knowledge spillovers, then team $i$ 's marginal cost of talent is lower than team $j$ 's $\left(p_{i}\left(a_{i}\right)<p_{j}\left(a_{j}\right)\right)$. With no exchange of talent between team $i$ and team $j$, the league outcome is pushed to the left of point $E_{1}$. Team $i$ acquires even more talent, and $W_{i}$ increases while team $j$, facing a higher marginal cost of talent, acquires less talent, decreasing $W_{j}$. The effects of agglomeration with no exchange of talent between the teams makes the competitive imbalance in the leagues worse, as team $i$ becomes stronger and team $j$ becomes weaker. In this case, agglomeration increases the equilibrium level of success of teams playing in dense urban areas relative to those playing in smaller, less dense cities.

If the teams can exchange players, and the pool of players in the agglomerated area is relatively small and fixed, then team $i$ will sell players to team $j$ at a price $p_{s}=M R_{a_{j}}^{j}>$ $P i\left(a_{j}\right)$ and earn a profit. The league will eventually return to the original equilibrium $E_{1}$, where team $i$ is still more successful than team $j$, but the league competitive balance is improved, relative to the outcome under agglomeration and no player exchange. However, many leagues place restrictions on the exchange of players for cash, which would reduce the tendency for the league to return to $E_{1}$. Also, it could be that players will be unwilling to move to smaller cities with fewer urban amenities, even with the higher salary paid by team $j$.

Even under player exchange, if the pool of players in the agglomerated area is large and can expand due to demographics, as new cohorts of children mature enough to be hired by teams, and the agglomerative effects are permanent, then the league outcome to 
the left of point $E_{1}$ could be permanent. In this case, teams that can take advantage of the localization benefits would be permanently better than teams located in areas with no localization benefits.

If the effect of agglomeration is to reduce team's fixed costs such that $F_{i}<F_{j}$, the allocation of talent across teams is unaffected because both teams face the same marginal cost of acquiring talent, $p_{1}$. However, team $i$ will be more profitable than team $j$, since team $i$ faces a lower total cost of producing any level of team success. In this case, team $i$ will still be more successful than team $j$ in equilibrium, because team $i$ still enjoys the benefits of urbanization, and has more, higher income fans to sell wins to than team $j$.

If localization effects increase the marginal revenue of teams located in the large urban area, then the marginal revenue curve for these teams, $M R_{i}$, will shift up farther than it would under only urbanization effects. This would increase the competitive imbalance in the league, as the teams in large urban areas would use the increased revenue from the localization economies to purchase even more talent. Localization economies could increase marginal revenues in a large urban area by fostering more, and stronger rivalries among fans of different teams, generating more, and more intense derby matches between specific pairs of teams. Derby matches would be less likely to occur among spatially differentiated teams, since their fans would not interact to the same degree as fans in large urban areas.

The model predicts that, under some conditions, localization and urbanization affect equilibrium league outcomes by improving the performance of teams in large urban areas and decreasing the performance of teams in smaller urban areas. (Doran and Jordan, 2018) show that football teams perform better when located near other football teams, a form of localization. Jones and Jordan (2019) develop evidence that urbanization affects football team performance, showing that football teams in more populated cites perform better. We next turn to an empirical analysis of football outcomes in the CP to develop evidence on the effect of localization and urbanization on football team performance in this setting. 


\section{Data and Econometric Approach}

\subsection{Data}

To analyze the impact of agglomeration on team productivity we use data from two sources. First, we scrape data from the Federação Paulista de Futebol (FPF) website, the organization that oversees professional football in São Paulo state. The FPF website contains information on team performance for each of the four divisions in the Campeonato Paulista for the 2007 to 2018 seasons. The structure of the competition in the four CP divisions changed over the sample period. Appendix Section A describes these changes.

The empirical analysis exploits promotion and relegation of teams between divisions to generate variation in the number of teams in different municipalities competing in each division in each season. This generates exogenous variation in localization of football teams in municipalities over time. Changes in the structure of the competition in each division provide additional variation in the composition of each division.

We also obtained information on the characteristics of each team competing in the CP, such as if they field an under 17 team, if they are considered a development team by the Confederação Brasileira de Futebol (CBF), whether the team plays in a private or public stadium, if this stadium is shared with another team, and each team's geolocation (official address). Figures 2 to 5 show the distribution of teams across municipalities in the state of São Paulo for each division in each season. We exploit the spatial and temporal variation shown in these figures, and the resulting changes in localization in each municipality-season in our empirical analysis.

\section{Team Success Measures}

We define short-term success of a team by its within-division performance in each season. Football team success can be reflected in many outcomes, so we use several success proxy 
variables: team win-loss ratio, goal differential, and points scored. The win-loss ratio reflects the ratio of win to losses, ignoring any draws. Because some teams had undefeated seasons, we add one to both wins and losses when computing the win-loss ratio.

Goal differential is calculated by subtracting the number of goals given up from the number of goals scored. Goal differential reflects the relative strength of teams' offensive and defensive ability. Goal differential reflects different types of team success than win-loss ratio. A team with a high win-loss ratio could have a small goal differential if the team wins a relatively large number of close games, or a large goal differential if the tea wins a relatively large number of games by a wide margin.

The number of points is the points earned by each team in each season. The CP follows international rules, awarding three points for a win, one point for a draw, and zero points for a loss. For seasons with additional knockout rounds after the group stage competition, we include the results of all matches. In other words, if a team wins it gets three points, however if there was a draw, leading to penalty kicks, we consider the result a draw.

We define long-term success using a novel Elo rating of CP football teams. Elo ratings are commonly used to rank teams in sports (Gásquez and Royuela, 2016; Lehmann and Wohlrabe, 2017). The Elo rating system is a relative skill ranking based on game-by-game outcomes. Appendix Section B contains detailed information on Elo-ratings.

Calculating an Elo rating requires initial values for teams. We use the 2007 season as benchmark and assign the value of 1500 to every team that did not play in the CP in that year. For teams that played in the CP in 2007, we rank-order them by their final position on the table in each division and add 3 points for each higher position in the ranking. In other words, the last place in Série A4 receives an initial Elo value of 1503, the second last 1506, and so on. The champion of in Série A1 receives 1779 points. The point difference in the Elo rating can be used to calculate the expected result of each match, $E(t)$, measured as the team's probability to win the match. Thus, for each team in a match $(t=i, j)$, the expected outcome is 


$$
E(t)=\frac{1}{1+10^{\frac{\left(R_{t=i}-R_{t=j}\right)}{400}}}
$$

where $R(t)$ is the strength of each team in terms of its current Elo rating. Suppose that team $i$ is the first place team in division A1 and team $j$ the last place team in division A4. The 279 point difference between the first place A1 Elo rating and the last place A4 Elo rating corresponds to a win probability of the first place team of $83.3 \%$.

Elo ratings compare the expected outcome of a game to the actual outcome and computes an updated Elo rating of each team. Define team t's match outcome $(O(t))$ as 1 , if it wins, 0.5 if there is a draw and 0 if it loses. The updated Elo-rating $\left(R^{N}\right)$ for each team is:

$$
R^{N}(t)=R(t-1)+K *(O(t)-E(t))
$$

where $R(t-1)$ is team $t$ 's previous Elo rating. $K$ is a factor reflecting how each match impacts a team's rating. In other words, $K$ is the maximum number of points a team can earn in each match. In this paper we use the value of 30, which is similar to the value used in other Elo rankings such as the United States Chess Federation $(K=32)$ and www.eloratings.net $(20 \leq K \leq 60)$. Note that football differs from other North-American leagues in that there is no draft system. Therefore, this creates a more structured ranking of teams with lower mobility. $E(t)$ is the expected score before the match is played. To implement the Elo calculations we use the package elo in R.

Elo ratings reflect long term team success, as they reflect all past game outcomes. In particular, $E(t)$ is a function of all past $E(t)$ for team $t$, which reflects all past performance conditional on the Elo rating of the opposing team.

In addition to the Elo rating, we also proxy long-term success by the team's probability of promotion, and probability of relegation over the sample period. For the probability of promotion and relegation we estimate a linear probability models in which the dependent variable is an indicator variable equal to 1 when a team was promoted or relegated at the 
end of the current season and equal to 0 when the team remained in the same division at the end of the season. Teams more likely to be promoted are more successful and team more likely to be relegated are less successful, relative to teams staying in the same division season after season.

These measures of long-term and short-term success can be interpreted as measures of overall team productivity holding labor and capital constant. Each team fields only eleven football players in each game, and the level of competition and playing talent increases across divisions from Série A4 at the bottom to Série A1 at the top. Teams of eleven football players in Série A1 are relatively more productive than teams of eleven football players in Série A4 because they play in a division with other more talented players and successful teams.

Table 1 provides summary statistics for the different success measures. Panel A contains the short-term success measures and Panel B the long-term measures. Notice that some teams have negative points. This occurred because they were punished by the FPF with losses of points for breaking FPF rules. Some teams went undefeated (zero losses) and winless (zero wins) in the sample period with an average of about 7 wins and 7 losses per season. From the long-term success measures, the average team played in division A3 (recall that division A4 contains more teams than the other three divisions) and faced an average probability of relegation of about $12.5 \%$ and an average probability of relegation of about $10 \%$.

\section{Localization and Urbanization Measures}

As discussed in the model developed above, we focus on two types of agglomeration variables: one type reflecting localization economies and another reflecting urbanization economies. In terms of localization economies, we start with the count of teams in each division in each municipality in each season 


$$
c_{d m y}=\sum_{t} T_{t d m y}-D C_{t}
$$

where $t$ indexes teams, $m$ indexes municipalities, $d$ where $d=1,2,3,4$, indexes divisions, and $T_{t d m y}$ identifies individual football teams. $D C_{t}$ is a function that equals one if team $T_{t d m y}$ plays in division $d=d_{c}$, team $t$ 's current season division, and zero otherwise. $D C_{t}$ avoids double counting team $T_{t d m y}$ in the current division-municipality-season and ensures that the team counts for each division-municipality-season include only other teams in the municipality.

One potential problem with using counts of teams as a localization measure is that they implicitly assume all municipalities have the same area. To address this we also calculate raw concentration measures proposed by Ellison and Glaeser (1997) and Maurel and Sédillot (1999) that take area into account. Overall, localization measures should take into account both geographical concentration and industrial concentration (Duranton and Overman, 2005; Ellison and Glaeser, 1997; Maurel and Sédillot, 1999). However, the industry concentration in the $\mathrm{CP}$ is determined by size of each division, which is determined by FPF and is fixed for all but division A4. Thus, any variation in the localization measure would come from changes in the geographical concentration.

Another possible concern with the localization measures that take into account geographical concentration is the impact of the creation of new municipalities. If this happens, then the within-municipality indexes would not be comparable across years. This is not an issue here. Since it is one of the oldest states in the country, most of its municipalities date back many years, and the newest municipality (Guatapará) was created in 1989, prior to the start of our sample. This represents another advantage of focusing on the state of São Paulo.

We follow Maurel and Sédillot (1999) and use the raw concentration measure in Ellison and Glaeser (1994) $(E G I)^{3}$ First define $x_{m}=\frac{\sum_{d} t_{m d}}{\sum_{d} \sum_{m} t_{m d}}$ as the share of all teams in

\footnotetext{
${ }^{3}$ In Ellison and Glaeser (1997) the raw concentration measure is equivalent to the version described in the working paper version (Ellison and Glaeser, 1994).
} 
municipality $m$. Then,

$$
E G I_{m}(d)=\frac{\left(s_{m}(d)-x_{m}\right)^{2}}{1-x_{m}^{2}}
$$

where $s_{m}(d)$ is share of teams in division $d$ in municipality $m$. Ellison and Glaeser (1997) show this index to be functionally related to the Hirschman-Herfindahl Index, but also accounts for a counterfactual spatial distribution of firms based on a random distribution over space (a "dartboard" approach). We also use the raw concentration measure developed by Maurel and Sédillot (1999) (MSI)

$$
M S I_{m}(d)=\frac{s_{m}(d)^{2}-x_{m}^{2}}{1-x_{m}^{2}}
$$

where $s_{m}(d)$ and $x_{m}$ are defined as above. This differs from the Ellison and Glaeser (1997) approach in the exact functional form used, and not in the variables used (the fraction of firms in each geographic area and the fraction of total area accounted for by each geographic area).

In the case of football outcomes, it does not make sense to expand the concentration measure to calculate the $\gamma$ concentration measure based on labor inputs contained in both Ellison and Glaeser (1997) and Maurel and Sédillot (1999), because the outcome of a season's competition depends on contests played between football teams of eleven players each, thus we would not get any additional information from the invariant labor inputs employed by each team.

Note that Duranton and Overman (2005) develop an alternative measure of localization based on the distance between each establishment/firm pair. In our set-up this location is less important, as teams have headquarters in different location from the stadium which they play. Also, some teams may share stadiums, especially if these are publicly owned. Given the historic formation of teams in Brazil, as described in Appendix Section A, the actual location of each team should be random conditional on the concentration of teams and the 
location of sports teams in the state. ${ }^{4}$

In terms of urbanization, we use population and median wage in each municipality as proxy variables. Population represents a standard measure of urbanization reflecting the size of a city in terms of residents. The median wage variable serves two purposes. As argued in section 2 the purchasing power of team supporters is of importance. However, more importantly, given the spatial equilibrium approach, wages plus local amenities should offset housing costs to ensure consumer indifference to location across space (Roback, 1982; Glaeser, 2007).

Table 2 presents descriptive statistics for each raw location measure, which were standardized to make the results comparable. These measures are shown by division. Panel A in table 3 presents descriptive statistics for each urbanization measures, that is, municipality population and median wage. These variables have also been standardized in the regression for comparability.

To control for time varying factors in each municipality, we collect data on employment, value added in production in the agriculture, government, manufacturing, and services industries, along with the total number of establishments and population in each municipality. These variables come from SEADE, a independent public agency sponsored by São Paulo state, and RAIS, an annual government report on Brazil's formal industries. Panel B in table 3 contains descriptive statistics for these variables.

\subsection{Econometric Approach}

We estimate the following equation explaining observed variation in team success/productivity to assess the impact of agglomeration economies (localization and urbanization) on team outcomes

\footnotetext{
${ }^{4}$ Using the longitude and latitude of team's official address, we also estimated models using the number of teams within a $50 \mathrm{~km}$ radius as a localization measure. The parameter estimates from this model are generally not statistically different from zero, and for those that are, they are in line with our main results presented below. These results are available on request.
} 


$$
T S_{t d m y}=\beta_{0}+\beta_{1}^{\prime} L O C_{d m y}+\beta_{2}^{\prime} U R B_{m y}+\beta_{3} X_{m y}+\mu_{t}+\mu_{d}+\mu_{m}+\mu_{y}+\varepsilon_{t d m y}
$$

where $T S_{t d m y}$ is the measure of football success of team $t$, in division $d$, in municipality $m$, in year/season $y . L O C_{d m y}$ is a vector of localization measures for division $d$ in each municipality $m$ in season $y$. These localization measures reflect conditions in all four divisions in all municipalities in each season. They reflect within division localization effects, for example the impact of localization from other teams playing in division A1 in municipality $m$ in season $y$ on outcomes for a team playing in division A1 ( $\left.T S_{t A 1 m y}\right)$, and across division effects, for example the impact of localization from teams playing in division A1 in municipality $m$ in season $y$ on outcomes for a team playing in division A3 $\left(T S_{t A 3 m y}\right)$. As discussed above, we cannot sign the parameters in $\beta_{1}^{\prime}$ a priori. Any statistically significant parameter estimates constitute evidence that localization economies affect the success/productivity of local football teams.

$U R B$ is a vector of municipality level urbanization variables including median wage and population density; $X$ is a vector of other control variables including the total municipality employment, total establishments (firms) in the municipality, population and value added by sector (agriculture, manufacturing, service, and government) in each municipality. $\mu_{t}, \mu_{d}, \mu_{m}$, $\mu_{y}$ are teams, division, municipality and year/season fixed effects; $\varepsilon_{t d m y}$ is the idiosyncratic error term. This is assumed to be mean zero and possibly heteroscedastic across teams. One important feature of $\mathrm{CP}$ is that teams only play teams within their own division in each season. Therefore, variation in success generated by matches between teams of different strengths is less of a concern in this setting. The parameter vectors of interest are $\beta_{1}$ and $\beta_{2}$, which capture the effects of localization and urbanization economies, respectively, on team productivity. To make our results comparable we standardize all localization and urbanization variables. 
To identify the impact of localization economies on team productivity, we exploit the promotion and relegation system in the Campeonato Paulista to generate exogenous variation in the level of localization, in terms of the number of teams in each division playing in each municipality in each season, and other localization variables described below. The bottom teams in each division are relegated no matter what city they play in, and the top teams in all divisions except division A1 are promoted. This generates both spatial and temporal variation in localization measures in each municipality in each season. The difference between relegation and remaining in the current division can be tiny because the system is rank ordered. A difference as small as one goal over the course of a season, or one draw that could have been a win or a loss, can make a difference between promotion or relegation and remaining in the same division. This should generate plausibly random spatial and season-to-season variation in localization.

The presence of so-called yo-yo teams represents one possible issue in this empirical analysis. A yo-yo team frequently experiences promotion and relegation, bouncing back and forth between divisions. We argue that these teams are not a concern because their promotion and relegation is exactly the variation we exploit. The localization and urbanization economies enjoyed by these teams may as well explain why they cannot build on their success and end up being relegated; or else, can keep some level of success which helps them being promoted. For our analysis to be biased, the only source of variation in success would have to come from yo-yo teams, which is not the case.

\section{Results}

Tables 4 to 9 contain the main results. Each column uses a different measure of localization of teams in each division in a municipality-season. Column (1) contains results using the count of teams as the localization measure ${ }^{5}$; column (2) contains results using the Ellison

\footnotetext{
${ }^{5}$ We also estimated models using the share of teams in as a localization measure as well, and the results are mostly not statistically significant. For those that are, they are in line with our main results presented
} 
and Glaeser (1997) raw concentration measure (EGI); column (3) contains results using the Maurel and Sédillot (1999) raw concentration measure (MSI). As explained above, we standardize all localization and urbanization proxy variables in order to generate comparable results in terms of parameter estimates.

All models reported on Tables 4 to 9 also contain time varying municipal characteristics and a variety of fixed effects as shown in Equation (12). We only report results for the variables reflecting localization and urbanization proxy variables. Results for all other explanatory variables are available on request. Standard errors are clustered at municipality level. For all results we discuss only those that are statistically significant and mostly focus on the sign.

First consider the short-term success/productivity outcomes. Table 4 contains the results defining success as the Win-Loss ratio $(W L)$ for each team in each season, Table 5 as Goal Differential $(G D)$, and Table 6 as the number of points $(\# P)$. Again, the model in section 2 cannot sign the parameters on these localization proxy variables. In general, the results on Tables 4, 5, and 6 contain evidence that localization economies affect local football team success/productivity. The general pattern is that a higher concentration of local teams playing in the top two divisions (A1 and A2) reduces local team short-run success, holding the number of local teams playing in lower divisions constant, and a higher concentration of local teams playing in the lower two divisions (A3 and A4) increases local team short-run success, holding the number of local teams playing in higher divisions constant.

This pattern may reflect the impact of local labor pooling and job matching, long identified as important sources of localization economies. Cities with many lower division teams and only a few upper division teams have a relatively large pool of developing players, coaches, and trainers that can be readily observed and evaluated, and the best ones can be hired away by the top teams. It could also reflect knowledge spill overs, to the extent that teams playing in lower divisions could experiment more with training practices or tactics below. These results are available on request. 
and these innovations could be easily observed by the teams playing in the higher divisions.

The negative sign on the variables reflecting concentration of teams playing in the higher divisions could also reflect the zero sum nature of within-division play in football. In cities with a large number of teams playing in division A1, all those teams play each other many times, and each win by one team must be a loss by a local rival team when the play each other.

The model in section 2 predicts that teams located in denser and higher wage municipalities should perform better. The results on Tables 4, 5, and 6 generally support this prediction. In terms of the urbanization economy proxy variables, the local median wage does not affect the short-term success of teams. But several of the parameter estimates on the population variable are positive and statistically different from zero. The size of these parameter estimates are large. For example, a one standard deviation increase in population increases the goal difference by around 30 which corresponds to roughly 2 standard deviations.

Next we turn our attention to the long-term success measures. Table 7 shows the results for the Elo rating success measure. ${ }^{6}$ Table 8 contains results for the probability of promotion $(P($ promote $))$ and Table 9 the results for the probability of relegation $(P$ (relegate $))$. Note that the signs of parameter estimates on Table 9 must be interpreted differently than on the other tables because the dependent variable takes a value of one for negative outcomes (relegation). So a negative sign on a parameter on this table means the team was more successful in that it avoided relegation.

In terms of the impact of localization economies, the results on Tables 7, 8, and 9 generally resemble the short run results on Tables 4, 5, and 6. a higher concentration of local teams playing in the top two divisions (A1 and A2) reduces local team long-run success, holding the number of local teams playing in lower divisions constant, and a higher concentration

\footnotetext{
${ }^{6}$ Appendix C show robustness checks for the Elo measure changing both the initial Elo ranking and the $k$ parameter that determines the amount of points available in each match. All results are consistent through all measures.
} 
of local teams playing in the lower two divisions (A3 and A4) increases local team longrun success, holding the number of local teams playing in higher divisions constant. The mechanisms that link localization economies and local team short-run success also apply to long-run success by local football teams.

With regard to urbanization externalities, median wage does not seem to explain team's long-term success when looking at the Elo, P(promote), P(relegate) outcome variables. Population has a positive and statistically significant effect on long term success for the Elo and $P($ relegate $)$ in the Count model, and the probability of playing division A4 in all three models. The results generally support the predictions from the model in section 2 in terms of the impact of urbanization externalities on long-run football team success.

Taken together, the results suggest that, as predicted by the model, urbanization externalities are important to explain both short-term and long-term success of teams. The evidence also supports the importance of localization effects, although the sign of this impact differs depending on the level of the local teams. This provides new insight into how agglomeration economies impact football team success.

To interpret the results in a different context, consider the case of Madrid, Spain. Madrid is home to one of the most successful teams in Spain, Real Madrid, winner of 33 top division titles, 19 domestic knock-out competition championships, and 13 pan-European club championships. A second successful team, Athletico, also plays in Madrid. The standard explanation for the prolonged success of Real Madrid and Athletico would be that the teams play in a large, high income city that provides important urbanization externalities that make these teams more successful. The results in this paper confirm that urbanization plays an important role, but in addition the presence of four other football teams in Madrid generally playing at lower levels also explains the success of Real Madrid, which enjoys the benefits of input sharing, job-market pooling and matching, and knowledge spillovers generated by the presence of other football teams in the area. Teams in other cities in Spain do not enjoy these large localization economies. 


\section{Conclusion}

This paper analyzes the importance of localization and urbanization economies in explaining firm productivity. We focus on Campeonato Paulista, a football competition played in São Paulo state, Brazil, and exploit its promotion and relegation structure to identify changes in team concentration across municipalities by division, a proxy for localization economies. The conceptual model makes clear predictions about the impact of urbanization economies on team success, but uncertain predictions about the impact of localization economies.

Using data for Campeonato Paulista for the 2007 to 2018 seasons, we find that localization economies positively impact team short-term and long-term productivity/success although the direction of the impact differs by division. Urbanization economies also affects team short-run and long-run success in the direction predicted by the model.

The implications of these results for sports leagues are two-fold. First, in the US context, with increasing movement of teams across cities, and renewed discussion of league expansion, these results can inform teams about how their location decision may affect their long-run level of success. In the European and Brazilian context, these results help to shed more light on why teams in larger cities continuously enjoy more success than those isolated in smaller markets.

In an urban economics context, team success represents a clean measure of firm productivity. In other settings, firm productivity could increase because of external factors like localization and urbanization economies, but could also reflect benefits from internal scale economies; estimates of productivity increases from localization could, in part, reflect unobservable internal scale economies. This is particularly important given the framework and institutions in a developing country. Football teams cannot put more than eleven players on the pitch at one time, and capital plays a very small role in team success. So more successful teams are more productive with the same level of labor and capital inputs as less successful teams. The localization effects estimated in this context are unlikely to be contaminated by unobservable internal scale economies. They also do not reflect selection, in terms of more 
productive firms entering cities with more agglomeration effects. Brazilian football teams rarely move from the neighborhoods where they initially formed decades ago.

These results allow us to speculate about what may happen in US leagues if entry/exit were to be allowed. These results suggest that we should expect that larger markets would attract more teams, and these teams would benefit from localization economies, making them more successful. The effect of urbanization economies alone, assuming new entrants cannibalize the existing sports market by taking fans from existing teams, implies that the entrance of new teams would reduce the success all teams in a large urban area. Also, we would not expect to see new franchises enter in isolated smaller cities, as they would not enjoy the benefits of either urbanization or localization economies.

\section{References}

Amorim Filho, M. H. and Silva, J. A. F. (2012). A gestão de clubes de futebol ? regulação, modernização e desafios para o esporte no Brasil. Revista Interesse Nacional.

Arrow, K. (1962). The economic implications of learning by doing. Review of Economic Studies, 29(3):155-173.

Devereux, M., Griffith, R., and Simpson, H. (2007). Firm location decisions, regional grants and agglomeration externalities. Journal of Public Economics, 91(3-4):413-435.

Doran, J. and Jordan, D. (2018). The effect of geographical proximity and rivalry on performance: evidence from the English Football League. Regional Studies, 52(11):1559-1569.

Driessen, G. A. and Sheffrin, S. M. (2017). Agglomeration, tax differentials, and the mobility of professional athletes. Public Finance Review, 45(2):283-302.

Duranton, G. and Overman, H. (2005). Testing for localization using micro-geographic data. Review of Economic Studies, 72(4):1077-1106.

El-Hodiri, M. and Quirk, J. (1971). An economic model of a professional sports league. Journal of Political Economy, 79(6):1302-1319.

Ellison, G. and Glaeser, E. (1994). Geographic concentration in U.S. manufacturing industries: a dartboard approach. NBER Working Paper 4840.

Ellison, G. and Glaeser, E. (1997). Geographic concentration in U.S. manufacturing industries: a dartboard approach. Journal of Political Economy, 105(5):889-927.

Elo, A. E. (1978). The Rating of Chessplayers, Past \& Present. Arco Publishing, New York, NY. 
Fort, R. and Quirk, J. (1995). Cross-subsidization, incentives, and outcomes in professional team sports leagues. Journal of Economic Literature, 33(3):1265-1299.

Galliano, D., Magrini, M.-B., and Triboulet, P. (2015). Marshall's versus Jacobs' externalities in firm innovation performance: The case of French industry. Regional Studies, 49(11):1840-1858.

Glaeser, E., Kallal, H. D., Scheinkman, J., and Shleifer, A. (1992). Growth in cities. Journal of Political Economy, 100(6):1126-52.

Glaeser, E. L. (1998). Are cities dying? The Journal of Economic Perspectives, 12(2):139160.

Glaeser, E. L. (2007). The economics approach to cities. Working Paper 13696, National Bureau of Economic Research.

Glaeser, E. L., Henderson, V., and Inman, R. P. (2000). The future of urban research: Nonmarket interactions [with comments]. Brookings-Wharton Papers on Urban Affairs, pages 101-149.

Glaeser, E. L., Kolko, J., and Saiz, A. (2001). Consumer city. Journal of Economic Geography, 1(1):27-50.

Glaeser, E. L. and Maré, D. C. (2001). Cities and skills. Journal of Labor Economics, $19(2): 316-342$.

Glaeser, E. L. and Xiong, W. (2017). Urban productivity in the developing world. Oxford Review of Economic Policy, 33(3):373-404.

Glickman, M. E. (1995). A comprehensive guide to chess ratings. American Chess Journal, 3:59-102.

Glickman, M. E. and Jones, A. C. (1999). Rating the chess rating system. Chance, 12(2):2128.

Groot, S. P., de Groot, H., and Smit, M. (2014). Regional wage differences in the Netherlands: Micro evidence on agglomeration externalities. Journal of Regional Science, 54(3):503-523.

Gásquez, R. and Royuela, V. (2016). The determinants of international football success: A panel data analysis of the Elo rating. Social Science Quarterly, 97(2):125-141.

Henderson, J. V. (2003). Marshall's scale economies. Journal of Urban Economics, 53(1):128.

Henrickson, K. E. (2012). Spatial competition and strategic firm relocation. Economic Inquiry, 50(2):364-379.

Jacobs, J. (1969). The economy of cities. Random House, New York. 
Jones, C. and Jordan, D. (2019). Agglomeration, urbanization and competitive performance: the natural experiment of English football. Regional Studies, Regional Science, 6(1):421438.

Lehmann, R. and Wohlrabe, K. (2017). Who is the 'journal grand master'? a new ranking based on the Elo rating system. Journal of Informetrics, 11(3):800 - 809.

Lima, M. A. (2002). As origens do futebol na Inglaterra e no Brasil. http://www.klepsidra.net/klepsidra14/futebol.html.

Marshall, A. (1895). Principles of Economics. MacMillan; London.

Maurel, F. and Sédillot, B. (1999). A measure of the geographic concentration in French manufacturing industries. Regional Science and Urban Economics, 29:575-604.

Mills, B. M., Mondello, M., and Tainsky, S. (2016). Competition in shared markets and Major League Baseball broadcast viewership. Applied Economics, 48(32):3020-3032.

Mondello, M., Mills, B. M., and Tainsky, S. (2017). Shared market competition and broadcast viewership in the National Football League. Journal of Sport Management.

Moomaw, R. L. (1988). Agglomeration economies: Localization or urbanization? Urban Studies, 25(2):150-161.

Quigley, J. M. (1998). Urban diversity and economic growth. The Journal of Economic Perspectives, 12(2):127-138.

Roback, J. (1982). Wages, rents, and the quality of life. Journal of Political Economy, 90(6):1257-1278.

Romer, P. (1986). Increasing returns and long-run growth. Journal of Political Economy, 94(5):1002-37.

Rosenthal, S. S. and Strange, W. C. (2004). Evidence on the nature and sources of agglomeration economies. Handbook of Regional and Urban Economics, 4:2119-2171.

Szymanski, S. (2009). Playbooks and checkbooks: An introduction to the economics of modern sports. Princeton University Press.

Veček, N., Mernik, M., and Črepinšek, M. (2014). A chess rating system for evolutionary algorithms: A new method for the comparison and ranking of evolutionary algorithms. Information Sciences, 277:656 - 679 .

Viladecans-Marsal, E. (2004). Agglomeration economies and industrial location: city-level evidence. Journal of Economic Geography, 4(5):565-582. 


\section{Figures and Tables}

Figure 2: Team Distribution for Division A1

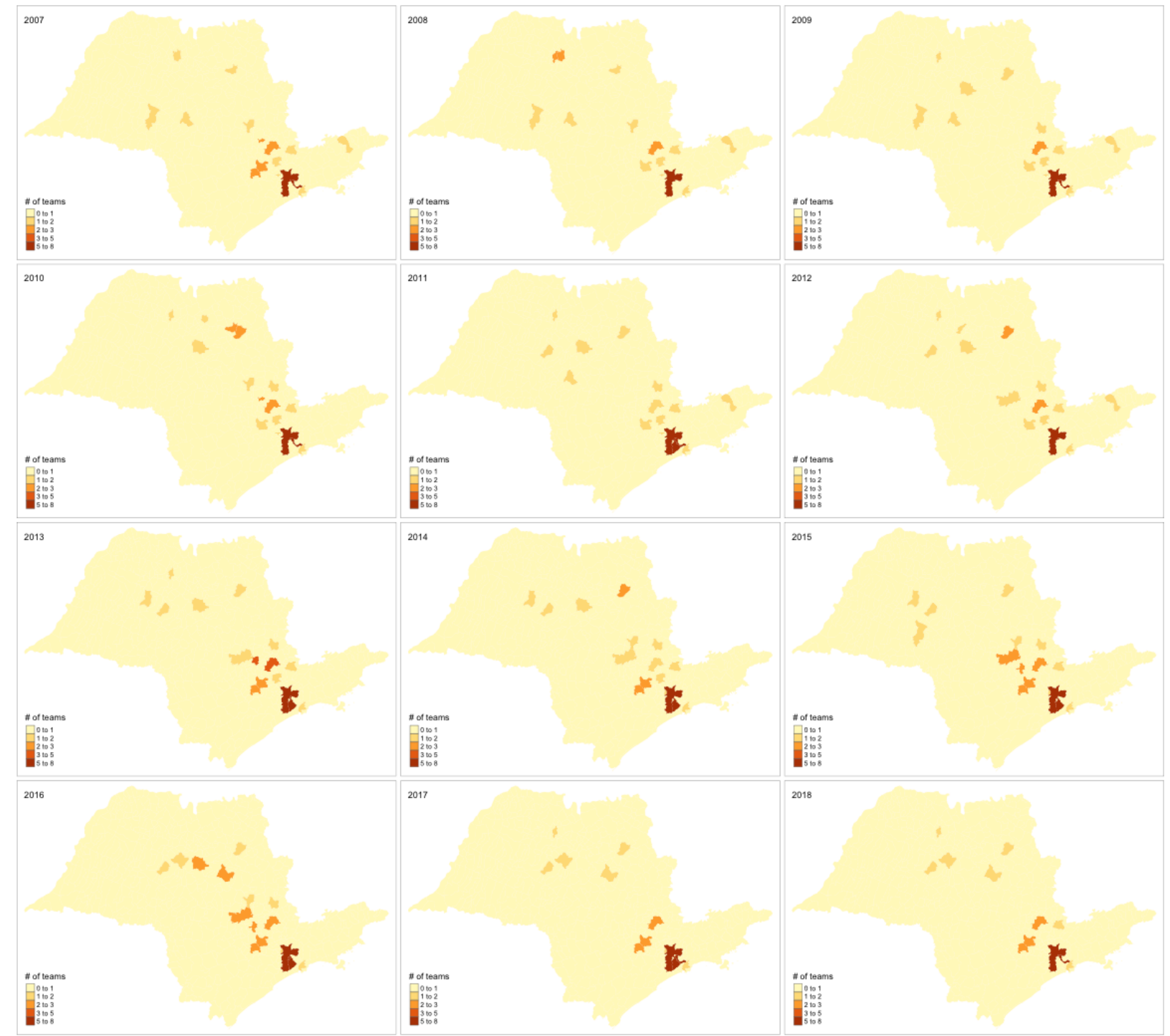


Figure 3: Team Distribution for Division A2

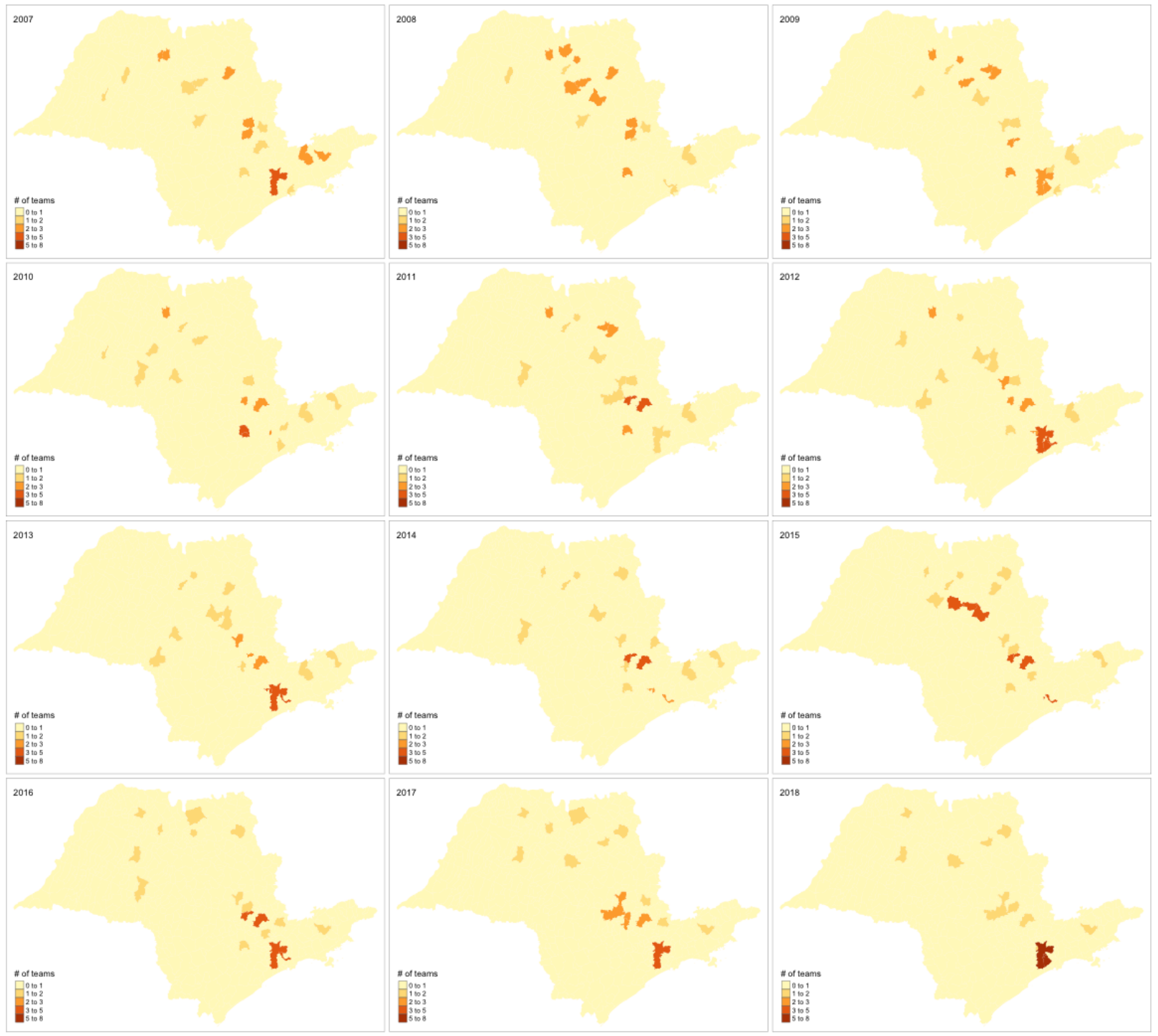


Figure 4: Team Distribution for Division A3

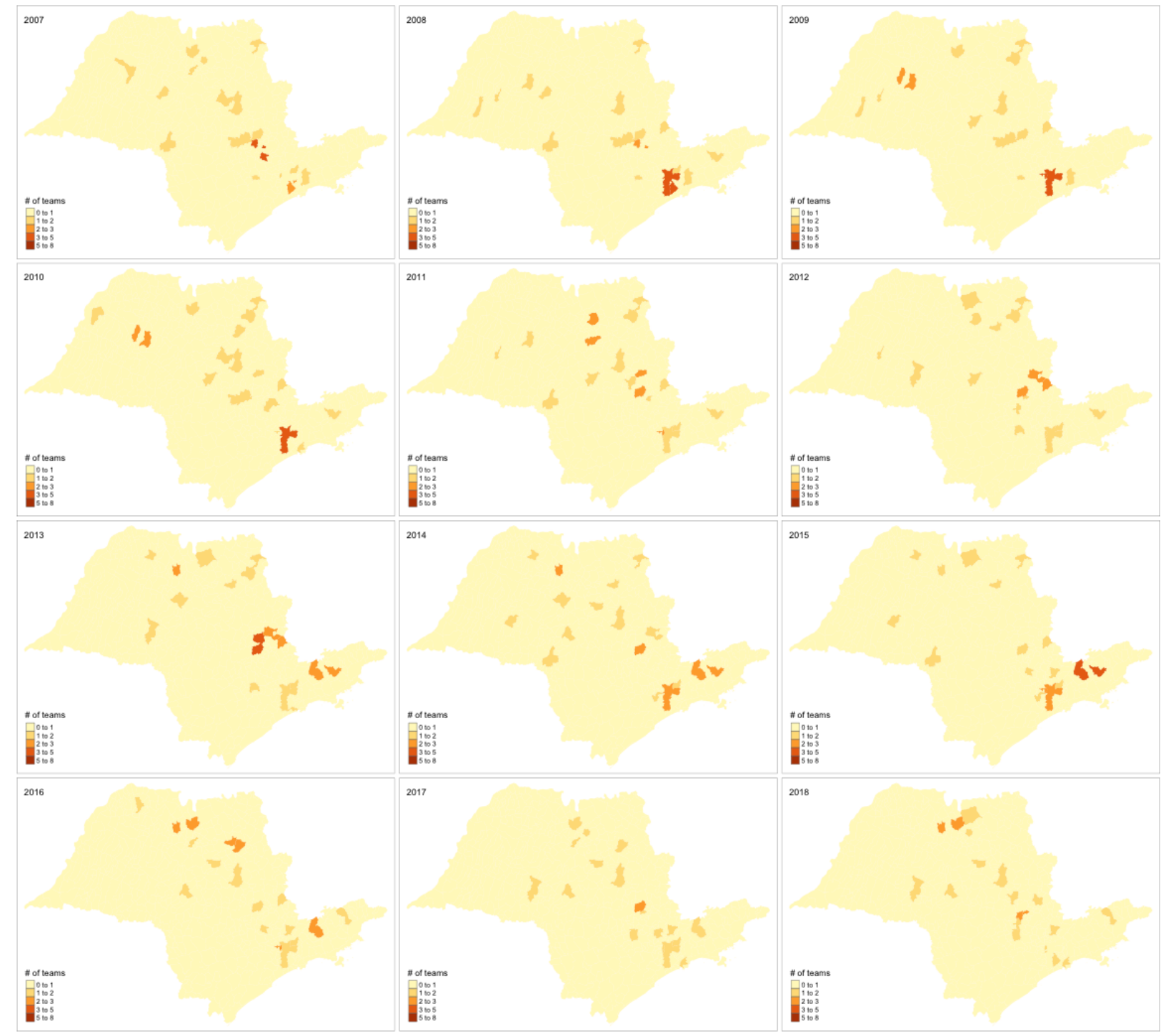


Figure 5: Team Distribution for Division A4

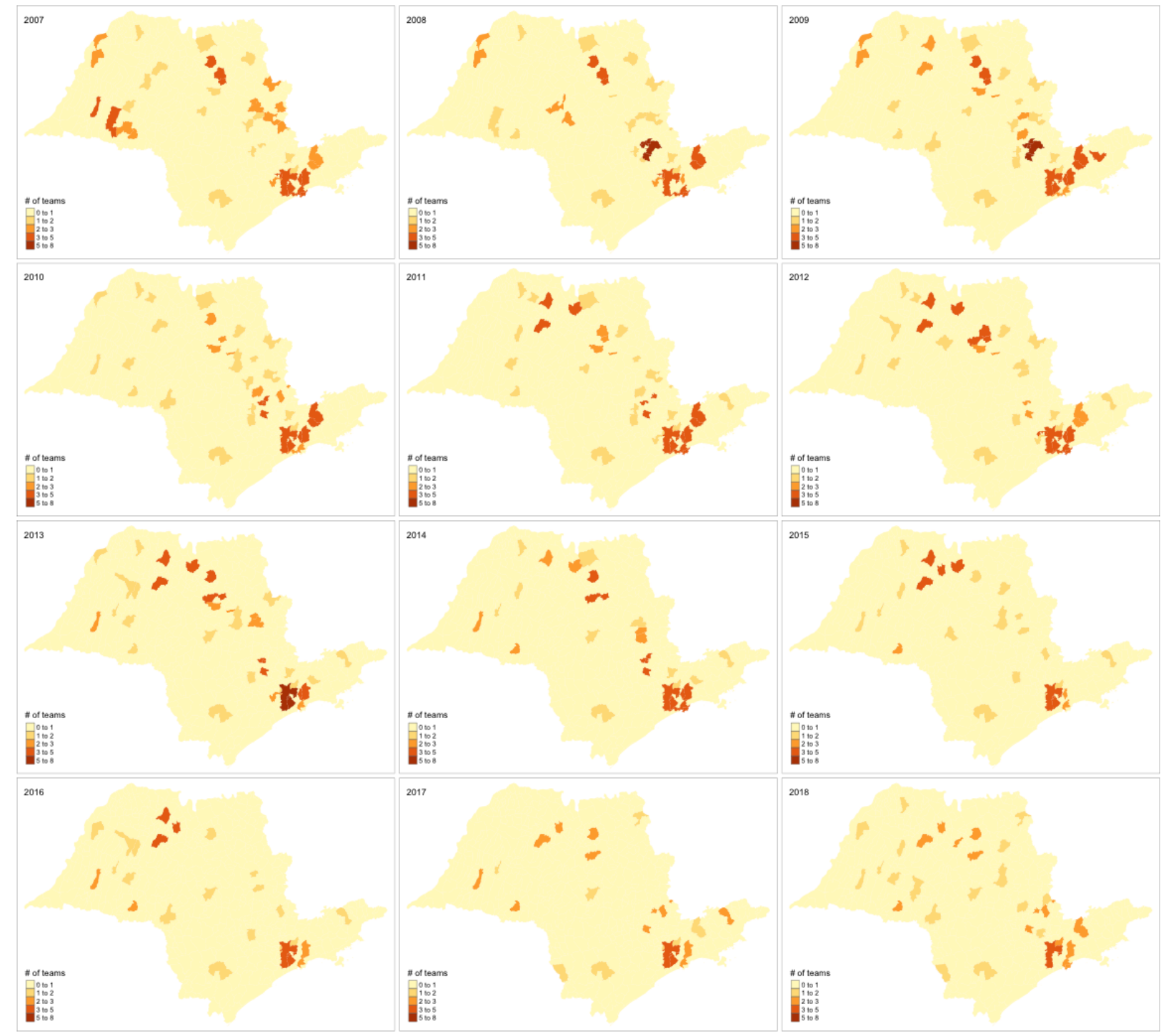


Table 1: Descriptive Statistics for Success Variables

\begin{tabular}{lccccc}
\hline \hline Statistic & $\mathrm{N}$ & Mean & St. Dev. & Min & Max \\
\cline { 1 - 3 } & & & & & \\
Paints & 1,194 & 26.3 & 14.0 & -12 & 70 \\
Wins & 1,194 & 7.26 & 4.23 & 0 & 22 \\
Losses & 1,194 & 7.27 & 2.68 & 0 & 19 \\
Goal Difference & 1,194 & -0.006 & 13.6 & -70 & 47 \\
& & & & & \\
Panel B: Long-term outcomes & & & & & \\
Elo Ranking & 1,183 & 1,635 & 142 & 1,217 & 2,088 \\
Relegated & 1,194 & 0.126 & 0.332 & 0 & 1 \\
Promoted & 1,194 & 0.106 & 0.307 & 0 & 1 \\
\hline
\end{tabular}


Table 2: Descriptive Statistics for Localization Measures by Division

\begin{tabular}{lccccc}
\hline \hline Statistic & $\mathrm{N}$ & Mean & St. Dev. & Min & Max \\
\cline { 1 - 2 } Panel A: Count & & & & & \\
Division A1 & 1,194 & 0.238 & 0.772 & 0.000 & 4.000 \\
Division A2 & 1,194 & 0.075 & 0.311 & 0.000 & 2.000 \\
Division A3 & 1,194 & 0.066 & 0.327 & 0.000 & 2.000 \\
Division A4 & 1,194 & 0.112 & 0.324 & 0.000 & 2.000 \\
& & & & & \\
Panel B: EGI & & & & & \\
Division A1 & 1,194 & 0.002 & 0.004 & 0.0001 & 0.024 \\
Division A2 & 1,194 & 0.001 & 0.002 & 0.0001 & 0.012 \\
Division A3 & 1,194 & 0.001 & 0.001 & 0.00001 & 0.007 \\
Division A4 & 1,194 & 0.0004 & 0.001 & 0.000 & 0.004 \\
& & & & & \\
Panel C: MSI & & & & & \\
Division A1 & 1,194 & 0.003 & 0.009 & -0.001 & 0.054 \\
Division A2 & 1,194 & 0.001 & 0.003 & -0.009 & 0.030 \\
Division A3 & 1,194 & 0.001 & 0.003 & -0.007 & 0.017 \\
Division A4 & 1,194 & -0.0001 & 0.002 & -0.007 & 0.004 \\
\hline
\end{tabular}

Number of teams in each division in whole sample: Division A1 = 232, Division A $2=236$, Division A3 $=240$, Division A $4=486$ 
Table 3: Descriptive Statistics for Control

\begin{tabular}{|c|c|c|c|c|c|}
\hline Statistic & $\mathrm{N}$ & Mean & St. Dev. & Min & $\operatorname{Max}$ \\
\hline \multicolumn{6}{|l|}{ Panel A: Urbanization measures } \\
\hline Population & 1,194 & $1,137,926$ & $2,956,281$ & 16,979 & $11,753,659$ \\
\hline Median Wage & 1,102 & 22.558 & 12.045 & 8.334 & 79.284 \\
\hline \multicolumn{6}{|l|}{ Panel B: Other Variables } \\
\hline Number of Firms & 1,102 & 27,426 & 72,379 & 517 & 306,156 \\
\hline Agriculture Value Added & 1,016 & 527 & 519 & 0 & 3,684 \\
\hline Manufacture Value Added & 1,016 & 65,270 & 145,619 & 106 & 668,601 \\
\hline Service Value Added & 1,016 & 320,298 & 908,629 & 1,153 & $4,760,035$ \\
\hline Public Administration Value Added & 1,016 & 30,456 & 79,150 & 368 & 393,752 \\
\hline Total Employment & 1,102 & 454,751 & $1,273,247$ & 3,007 & $5,308,401$ \\
\hline
\end{tabular}


Table 4: Short-Term Success: Win-Loss ratio

\begin{tabular}{lccc}
\hline \hline & \multicolumn{3}{c}{ Dependent variable: Win-Loss ratio } \\
\cline { 2 - 4 } & Count & EGI & MSI \\
\hline Division A1 & $-0.263^{* * *}$ & $-0.246^{* * *}$ & -0.211 \\
& $(0.083)$ & $(0.068)$ & $(0.143)$ \\
Division A2 & 0.023 & -0.051 & 0.044 \\
& $(0.040)$ & $(0.067)$ & $(0.084)$ \\
Division A3 & -0.038 & 0.022 & -0.021 \\
& $(0.073)$ & $(0.023)$ & $(0.077)$ \\
Division A4 & -0.018 & $0.203^{* *}$ & 0.105 \\
& $(0.054)$ & $(0.102)$ & $(0.181)$ \\
Median Wage & 0.361 & 0.429 & 0.338 \\
& $(0.398)$ & $(0.406)$ & $(0.403)$ \\
Population & -0.124 & $1.960^{* *}$ & -0.440 \\
& $(1.225)$ & $(0.875)$ & $(1.040)$ \\
R-squared & 0.407 & 0.410 & \\
\hline \hline
\end{tabular}

Clustered standard errors at municipality level in parentheses. $\mathrm{N}=1,016 ;{ }^{*} \mathrm{p}<0.1 ;{ }^{* *} \mathrm{p}<0.05 ;{ }^{* * *} \mathrm{p}<0.01$. Control variables: value added for agriculture, manufacturing, services and government, number of firms and formal employment. Team, division, municipality and year fixed effects are included in all regressions. 
Table 5: Short-Term Success: Goal Difference

\begin{tabular}{|c|c|c|c|}
\hline & \multicolumn{3}{|c|}{ Dependent variable: Goal Diff. } \\
\hline & Count & EGI & MSI \\
\hline \multirow[t]{2}{*}{ Division A1 } & $-2.493^{* *}$ & -0.271 & -1.656 \\
\hline & $(1.073)$ & $(0.859)$ & $(1.893)$ \\
\hline \multirow[t]{2}{*}{ Division A2 } & $-0.736^{*}$ & $-0.629^{*}$ & -0.735 \\
\hline & $(0.424)$ & $(0.370)$ & $(0.850)$ \\
\hline \multirow[t]{2}{*}{ Division A3 } & 0.592 & 0.499 & 0.348 \\
\hline & $(0.674)$ & $(0.636)$ & $(0.692)$ \\
\hline \multirow{2}{*}{ Division A4 } & 0.099 & 1.287 & 0.070 \\
\hline & $(0.539)$ & $(1.267)$ & $(1.728)$ \\
\hline \multirow[t]{2}{*}{ Median Wage } & 3.122 & 3.061 & 3.078 \\
\hline & $(5.999)$ & $(5.967)$ & $(6.056)$ \\
\hline \multirow[t]{2}{*}{ Population } & $32.684^{* *}$ & $26.783^{* *}$ & $30.687^{*}$ \\
\hline & $(15.844)$ & $(12.702)$ & $(17.887)$ \\
\hline R-squared & 0.395 & 0.395 & 0.394 \\
\hline
\end{tabular}

Clustered standard errors at municipality level in parentheses. $\quad \mathrm{N}=1,016 ;{ }^{*} \mathrm{p}<0.1 ;{ }^{* *} \mathrm{p}<0.05$; ${ }^{* * *} \mathrm{p}<0.01$. Control variables: value added for agriculture, manufacturing, services and government, number of firms and formal employment. Team, division, municipality and year fixed effects are included in all regressions. 
Table 6: Short-Term Success: Points

\begin{tabular}{|c|c|c|c|}
\hline & \multicolumn{3}{|c|}{ Dependent variable: \# Points } \\
\hline & Count & EGI & MSI \\
\hline Division A1 & $\begin{array}{l}-2.041 \\
(1.932)\end{array}$ & $\begin{array}{l}-0.053 \\
(1.112)\end{array}$ & $\begin{array}{l}0.206 \\
(2.456)\end{array}$ \\
\hline Division A2 & $\begin{array}{l}-0.152 \\
(0.476)\end{array}$ & $\begin{array}{l}-0.129 \\
(0.367)\end{array}$ & $\begin{array}{c}0.500 \\
(0.955)\end{array}$ \\
\hline Division A3 & $\begin{array}{c}1.029 \\
(0.675)\end{array}$ & $\begin{array}{c}0.848 \\
(0.646)\end{array}$ & $\begin{array}{c}1.100 \\
(0.706)\end{array}$ \\
\hline Division A4 & $\begin{array}{c}0.718 \\
(0.458)\end{array}$ & $\begin{array}{c}2.031 \\
(1.315)\end{array}$ & $\begin{array}{l}2.895^{* *} \\
(1.304)\end{array}$ \\
\hline Median Wage & $\begin{array}{c}3.480 \\
(5.187)\end{array}$ & $\begin{array}{c}3.884 \\
(5.184)\end{array}$ & $\begin{array}{l}3.613 \\
(5.207)\end{array}$ \\
\hline Population & $\begin{array}{c}23.779 \\
(17.059)\end{array}$ & $\begin{array}{c}20.099 \\
(15.788)\end{array}$ & $\begin{array}{c}10.570 \\
(19.228)\end{array}$ \\
\hline R-squared & 0.383 & 0.384 & 0.384 \\
\hline
\end{tabular}

Clustered standard errors at municipality level in parentheses. $\mathrm{N}=1,016 ;{ }^{*} \mathrm{p}<0.1 ;{ }^{* *} \mathrm{p}<0.05$; ${ }^{* * *} \mathrm{p}<0.01$. Control variables: value added for agriculture, manufacturing, services and government, number of firms and formal employment. Team, division, municipality and year fixed effects are included in all regressions. 
Table 7: Long-Term Success: Elo

\begin{tabular}{|c|c|c|c|}
\hline & \multicolumn{3}{|c|}{ Dependent variable: Elo score } \\
\hline & Count & EGI & MSI \\
\hline Division A1 & $\begin{array}{c}-7.139 \\
(10.105)\end{array}$ & $\begin{array}{l}-3.121 \\
(4.894)\end{array}$ & $\begin{array}{c}-5.470 \\
(14.862)\end{array}$ \\
\hline Division A2 & $\begin{array}{l}-1.233 \\
(3.479)\end{array}$ & $\begin{array}{l}-0.684 \\
(3.114)\end{array}$ & $\begin{array}{l}-0.615 \\
(7.066)\end{array}$ \\
\hline Division A3 & $\begin{array}{l}5.994^{* *} \\
(2.682)\end{array}$ & $\begin{array}{c}6.101^{* * *} \\
(1.955)\end{array}$ & $\begin{array}{l}4.205 \\
(2.910)\end{array}$ \\
\hline Division A4 & $\begin{array}{l}4.301 \\
(5.162)\end{array}$ & $\begin{array}{c}5.447 \\
(7.995)\end{array}$ & $\begin{array}{c}0.110 \\
(16.667)\end{array}$ \\
\hline Median Wage & $\begin{array}{c}30.375 \\
(30.947)\end{array}$ & $\begin{array}{c}32.698 \\
(31.496)\end{array}$ & $\begin{array}{c}32.698 \\
(31.651)\end{array}$ \\
\hline Population & $\begin{array}{c}154.909^{* *} \\
(68.102)\end{array}$ & $\begin{array}{l}100.485 \\
(66.526)\end{array}$ & $\begin{array}{l}132.123 \\
(83.302)\end{array}$ \\
\hline R-squared & 0.840 & 0.840 & 0.839 \\
\hline
\end{tabular}

Clustered standard errors at municipality level in parentheses. $\mathrm{N}=1,007 ;{ }^{*} \mathrm{p}<0.1 ;{ }^{* *} \mathrm{p}<0.05$; ${ }^{* * *} \mathrm{p}<0.01$. Control variables: value added for agriculture, manufacturing, services and government, number of firms and formal employment. Team, division, municipality and year fixed effects are included in all regressions. Elo score calculated with $k=30$ and initial ranking with point differential of 3 for each position. 
Table 8: Long-Term Success: Promotion

\begin{tabular}{|c|c|c|c|}
\hline & \multicolumn{3}{|c|}{ Dependent variable: $P$ (promoted) } \\
\hline & Count & EGI & MSI \\
\hline Division A1 & $\begin{array}{c}-0.108^{*} \\
(0.061)\end{array}$ & $\begin{array}{l}-0.016 \\
(0.042)\end{array}$ & $\begin{array}{l}-0.035 \\
(0.073)\end{array}$ \\
\hline Division A2 & $\begin{array}{l}-0.020 \\
(0.022)\end{array}$ & $\begin{array}{l}-0.015 \\
(0.025)\end{array}$ & $\begin{array}{l}-0.010 \\
(0.044)\end{array}$ \\
\hline Division A3 & $\begin{array}{c}-0.0004 \\
(0.022)\end{array}$ & $\begin{array}{c}0.015 \\
(0.025)\end{array}$ & $\begin{array}{l}-0.001 \\
(0.022)\end{array}$ \\
\hline Division A4 & $\begin{array}{l}0.021^{*} \\
(0.012)\end{array}$ & $\begin{array}{c}0.018 \\
(0.035)\end{array}$ & $\begin{array}{l}0.068^{*} \\
(0.037)\end{array}$ \\
\hline Median Wage & $\begin{array}{c}0.038 \\
(0.093)\end{array}$ & $\begin{array}{c}0.049 \\
(0.095)\end{array}$ & $\begin{array}{c}0.037 \\
(0.094)\end{array}$ \\
\hline Population & $\begin{array}{c}0.505 \\
(0.339)\end{array}$ & $\begin{array}{c}0.490 \\
(0.300)\end{array}$ & $\begin{array}{c}0.233 \\
(0.368)\end{array}$ \\
\hline R-squared & 0.241 & 0.238 & 0.240 \\
\hline
\end{tabular}

Clustered standard errors at municipality level in parentheses. $\quad \mathrm{N}=1,016 ;{ }^{*} \mathrm{p}<0.1 ;{ }^{* *} \mathrm{p}<0.05$; ${ }^{* * *} \mathrm{p}<0.01$. Control variables: value added for agriculture, manufacturing, services and government, number of firms and formal employment. Team, division, municipality and year fixed effects are included in all regressions. 
Table 9: Long-Term Success: Regelation

\begin{tabular}{lccc}
\hline \hline & \multicolumn{3}{c}{ Dependent } \\
\cline { 2 - 4 } & Count & EGI & MSI \\
\hline Division A1 & 0.023 & -0.041 & -0.056 \\
& $(0.043)$ & $(0.033)$ & $(0.052)$ \\
Division A2 & 0.005 & -0.012 & -0.015 \\
& $(0.014)$ & $(0.010)$ & $(0.024)$ \\
Division A3 & $-0.035^{*}$ & 0.011 & $-0.037^{*}$ \\
& $(0.019)$ & $(0.028)$ & $(0.021)$ \\
Division A4 & 0.004 & $-0.090^{* *}$ & -0.021 \\
& $(0.013)$ & $(0.038)$ & $(0.039)$ \\
Median Wage & 0.066 & 0.075 & 0.072 \\
& $(0.101)$ & $(0.097)$ & $(0.099)$ \\
Population & $-0.517^{*}$ & -0.479 & -0.321 \\
& $(0.297)$ & $(0.351)$ & $(0.274)$ \\
R-squared & 0.277 & 0.280 & 0.277 \\
\hline \hline
\end{tabular}

Clustered standard errors at municipality level in parentheses. $\quad \mathrm{N}=1,016 ;{ }^{*} \mathrm{p}<0.1 ;{ }^{* *} \mathrm{p}<0.05$; ${ }^{* * *} \mathrm{p}<0.01$. Control variables: value added for agriculture, manufacturing, services and government, number of firms and formal employment. Team, division, municipality and year fixed effects are included in all regressions. 


\section{A The Campeonato Paulista}

The Campeonato Paulista (CP), commonly called Paulistão, is the professional football competition in the state of São Paulo in Brazil. This is the oldest and most traditional state competition in the country. Its first competition dates to 1901; 102 different teams competed in it. As a brief historic background, the CP was founded by Charles Miller in 1901 and the players competing in the CP became professionalized in 1933. In this year, the CP made history as the first professional football tournament in Brazil. In 1941, the Federação Paulista de Futebol (FPF), the football confederation in São Paulo state, was founded and since then is the organization responsible for Paulistão. In the next two sections we discuss some of the institutional details of the $\mathrm{CP}$, such as the division structure and details of team formation, management, and player transactions.

\section{A.1 Division Structure and Organization}

CP uses a promotion-relegation system and an annual schedule. Since 1901, the CP has used several different competition formats, including a variable number of tiers of competition and different numbers of teams in each tier. Currently, there are four tiers or divisions in the CP: Série A1, A2, A3 and Segunda Divisão (Série A4 henceforth). Série A1 is the top division. Série A1, A2 and A3 matches are played between January and May; Série A4 matches are played between April and November. Below we summarize each division's rules and structure in each of the years in the sample?

Série A1 contains 20 teams. The four teams at the bottom of the table are relegated to Série A2 at the end of each season. Between 2007 and 2016 the Série A1 season had four different formats. From 2007 to 2010, there were three stages in the competition. In the first stage, every team played each other and the four teams with the fewest points were relegated; the top four teams would play in the second stage knockout round, with the first place team facing the fourth place team and the second place team facing the third place

\footnotetext{
${ }^{7}$ These are based on the information provided by FPF at http://futebolpaulista.com.br/Home/
} 
team. The winners would face each other in the third, championship stage.

From 2011 to 2013, the first stage format was maintained, but 8 teams qualified for the second stage knockout round. From 2014 on, in the first stage, the teams were divided into 4 groups of 5 teams, and the top two teams in each group faced each other in the second knockout round. The bottom four teams at the end of the first stage were still relegated to Série A2 in all seasons. In 2017, CP distributed around $\mathrm{R} \$ 12$ million Brazilian Reais in prize money to teams, compared to $\mathrm{R} \$ 10$ million in 2016.

Série A2, which contains 20 clubs, also used several formats in the sample period. From 2007 to 2009 and from 2012 to 2013, the 20 clubs would play each other in a first stage double round-robin competition, after which the 4 worst teams were relegated to Série A3. The top 8 clubs advanced to a second stage of group play. These 8 clubs were divided into two groups of four and played a second round-robin competition. The winner of each group would then play for the championship and the top two teams in each group would be promoted to Série A1.

In 2010, the format was similar, but there was no final match between the second-stage group winners. In 2011 the 20 clubs were divided into 2 groups of 10 in the first round. In 2014 and 2015 there was a single round with teams facing each other once. The four top teams were promoted to Série A1 and the top team was the champion, while the four worst were relegated to Série A3.

In 2016 the Série A2 format was quite different. There were 4 rounds of play. In the first round the 20 clubs played each other once and the four bottom clubs were relegated. The eight best advanced to a second knockout round. The four remaining teams in the semi-finals were promoted to Série A.

Série A3 had the most consistent format over the sample period. In all the analyzed seasons 20 teams played a double round-robin stage with the top 4 promoted to Série A2 and the bottom 4 relegated to the Segunda Divisão (Série A4). In 2016, however, 6 teams were relegated instead of 4. From 2007 to 2016, with exception of 2011, the 20 teams faced 
each other. The 8 best teams of were then divided into two groups in the second round. The teams played group members twice and the groups' winner faced each other on the finals. The two best teams in each group of the second round were promoted to Série A2. The difference in 2011 is that in the first round the teams were divided into two groups of 10 playing each other twice (within group only).

Série A4 (Segunda Divisão) is the division with the most variable season formats. The division contracted from 48 teams in 2007 to 32 teams in 2016. Overall the division format can be summarized as follows. The first round would have teams divided into 4 to 7 groups. In the second round 12 to 24 teams would be divided into 4 or 6 groups and play each other. In the third round there would be either 2 groups of 4 teams or a knockout-style final stage. The forth round would be wither the semi-finals for cup-style format or else the final between the winners of each group. The fifth-round, when in place was the final in the cup-style format. The best 4 teams - those in the semi-finals or else the two best in each group in the round prior to the final - are promoted to Série A3. An extra feature of this division is that, even though this is the only feeder to Série A3, players must be under 23 years-old.

As in any promotion and relegation system, the quality of play, the talent of players, and attendance increase in higher divisions. Série A1 contains the best teams, the most talented and highly paid players, and plays before the largest crowds. Série A2 contains the next best teams, and so on.

Although there are costs associated with promotion, such as hiring extra talent, the benefits from promotion should, on average, exceed the costs. For instance, promoted teams have access to a larger prize pool and attract larger crowds to games. Also, promotion increases team visibility, which should help reduce search costs for talent and increase their revenues from sponsors. 


\section{A.2 Team Formation, Management and Player Movement}

The process of football team formation in Brazil generally occurred long ago; few teams have been formed in recent times (Lima, 2002). In brief, football teams in Brazil were formed by social (athletic) clubs, neighborhoods, and as a part of industrial unions. Therefore, Brazilian clubs are not privately owned and do not have publicly traded shares. Instead teams are controlled by members associated with social or neighborhood clubs. This means that football teams in Brazil never relocate to different towns or regions ${ }^{8}$.

In terms of team management, Amorim Filho and Silva (2012) summarize the evolution of Brazilian football team management and the transition to professional management of clubs and leagues. The biggest change occurred in 1998 with the passage of the "general law of sports", or the so-called "Pelé Law" (Law n. 9615/98). This law required that all Brazilian football clubs became business enterprises. It also eliminated club "ownership" of athletes, who now could negotiate contracts with any club, creating free agency in Brazilian football.

Even though clubs became business enterprises after 1988, there still exist critics of this system. In general, teams have a Board of Directors called "Conselho Deliberativo". The Board will be composed of two types of directors: those who are elected by teams' associates and meritorious directors. The meritorious directors are permanent members of the board who obtain this position after making a significant monetary contribution to the team. The Board of Directors elects a president who runs the club for a three-to-four year period. Members of the Board also participate in the team's management in different functional areas such as marketing, finance, etc.

Amorim Filho and Silva (2012) identify two important features of standard firms that are not present in the football business in Brazil. First, there is little accountability for poor management, such as persistent financial losses. Second, the absence of payment to Board members who run the team's day-to-day operations creates rent-seeking behavior by board

\footnotetext{
${ }^{8}$ There is some anecdotal evidence of a few clubs being bought by private firms and relocated. These are very rare occurrences.
} 
members who may act in their own self interest by tying themselves to players rights or embezzling money.

In terms of player movement, there are two periods in which most player transactions occur: December and January, at the end of the season; and between May and July when transactions in Europe occur. Note that between February and May it is possible for teams to hire and register new players in the CP. However, these transactions are rare, as the bulk of transactions happen before the season starts and after the state championship ends, as this coincides with the beginning of the national league and the European hiring season.

Finally, unlike some American leagues like the NBA and NFL which enforce a cap on total player salaries and operate an entry draft to maintain competitive balance in the league, no such restrictions exist in Brazilian football. This is also true in Europe, in which although there is some cap on expenditures, there is no draft system in place. As a consequence, powerhouse clubs are common in football leagues since they are able to hire more talent through an increase in expenditures. ${ }^{9}$

\footnotetext{
${ }^{9}$ In Brazil, there is a large concern with the excessive expenditure to hire players that lead clubs to have a high debt level. Several programs have been put in place by the Brazilian government to help clubs reduce their debts.
} 


\section{B Elo ranking}

The Elo rating has been used by the International Chess Federation since 1970, and is the most common chess rating system in use (Glickman, 1995; Veček et al., 2014). According to Glickman (1995), the Elo rating system consists of a numerical rating, typically in between 0 and 3000 points, that changes over time conditional on the outcome of matches.

One of the benefits of the Elo rating is its simplicity (Veček et al., 2014). The current rating is interpreted as the player strength, which is used to predict the outcome of a match. Players with higher rating are expected to win more often. Following Glickman and Jones (1999), in a game two teams $(t) A$ and $B$, with strengths $R_{A}$ and $R_{B}$, the expected score or outcome $(E)$ for a team $A$ is:

$$
E_{A}=\frac{1}{1+10^{\frac{-\left(R_{A}-R_{B}\right)}{400}}}
$$

Table 10 shows the winning probabilities of each team based on the strength differential. The actual outcome $(O)$ of the game equals 1 if team $A$ wins, 0.5 if it is a draw and 0 if team $A$ loses. Thus, given the difference between the actual and expected outcome, the strength

of teams (i.e., their Elo rating) are updated. The updated Elo rating $\left(R^{N}\right)$ for team $A$, then, is calculated as:

$$
R_{A}^{N}=R_{A}+K\left(O-E_{A}\right)
$$

where $K$ is an attenuation factor, or else, a weight factor. The $K$ factor represents how fast the rating can evolve (Lehmann and Wohlrabe, 2017). The U.S. Chess Federation uses $K=32$ for weakest players and $K=24,16$ for stronger players $(R \geq 2100,2400)$. Another interpretation for the $K$ factor is the maximum amount of points a team can get in a particular match. Note that in the Elo rating, teams win or lose the same amount of points per match. In addition, the more matches played, the closer to the actual strength is the Elo rating. 
Let us illustrate the Elo rating for two hypothetical teams $A$ and $B$ after they play each other. Assume that $R_{A}=1600$ and $R_{B}=1750$. Based on their current strength we can predict the outcome of match:

$$
\begin{aligned}
& E_{A}=\frac{1}{1+10 \frac{-(1600-1750)}{400}}=0.30 \\
& E_{B}=\frac{1}{1+10 \frac{-(1750-600)}{400}}=0.70
\end{aligned}
$$

That are three possible outcomes, team $A$ wins, team $B$ wins, or else, there is a draw. If team $A$ wins or there is a draw, then we will observe an increase in team's $A$ rating. In both cases the actual outcome (1 or 0.5 ) is higher than the expected outcome of this game. Assuming, like in the main text, $K=30$, then the updated Elo ratings would be:

\section{Team $A$ wins:}

$$
\begin{aligned}
& R_{A}^{N}=1600+30 \times(1-0.3)=1621 \\
& R_{B}^{N}=1750+30 \times(0-0.7)=1729
\end{aligned}
$$

Team $B$ wins:

$$
\begin{aligned}
& R_{A}^{N}=1600+30 \times(0-0.3)=1591 \\
& R_{B}^{N}=1750+30 \times(1-0.7)=1759
\end{aligned}
$$

\section{Draw:}

$$
R_{A}^{N}=1600+30 \times(0.5-0.3)=1506
$$




$$
R_{B}^{N}=1750+30 \times(0.5-0.7)=1744
$$

Note that because team $A$ is expected to lose the game, the effect of an upset on the rating larger than if the expected outcome is in fact observed. For more on the Elo system one should refer to Elo (1978).

Table 10: Winning Probabilities based on rating differential

\begin{tabular}{ccc}
\hline \hline Rating Difference & Higher Rated & Lower Rated \\
\hline 0 & 0.50 & 0.50 \\
25 & 0.54 & 0.46 \\
50 & 0.57 & 0.43 \\
100 & 0.64 & 0.36 \\
150 & 0.70 & 0.30 \\
200 & 0.76 & 0.24 \\
300 & 0.85 & 0.15 \\
500 & 0.95 & 0.05 \\
800 & 0.99 & 0.01 \\
\hline \hline
\end{tabular}

Note: Calculated using equation 13. 


\section{Robustness Checks}

Appendix C1: Robustness Elo $2-k=10$ and point difference $=3$

\begin{tabular}{|c|c|c|c|}
\hline & \multicolumn{3}{|c|}{ Dependent variable: elo score 2} \\
\hline & Count & EGI & MSI \\
\hline Division A1 & $\begin{array}{c}-6.290 \\
(10.763)\end{array}$ & $\begin{array}{l}-3.651 \\
(4.943)\end{array}$ & $\begin{array}{c}-4.356 \\
(14.939)\end{array}$ \\
\hline Division A2 & $\begin{array}{l}-0.460 \\
(3.288)\end{array}$ & $\begin{array}{l}-0.042 \\
(2.684)\end{array}$ & $\begin{array}{c}1.012 \\
(6.683)\end{array}$ \\
\hline Division A3 & $\begin{array}{l}6.714^{* *} \\
(2.697)\end{array}$ & $\begin{array}{c}6.462^{* * *} \\
(1.975)\end{array}$ & $\begin{array}{l}4.971^{*} \\
(2.778)\end{array}$ \\
\hline Division A4 & $\begin{array}{c}4.183 \\
(4.925)\end{array}$ & $\begin{array}{c}6.001 \\
(7.830)\end{array}$ & $\begin{array}{c}-0.093 \\
(16.191)\end{array}$ \\
\hline Median Wage & $\begin{array}{c}32.285 \\
(30.559)\end{array}$ & $\begin{array}{c}34.643 \\
(31.073)\end{array}$ & $\begin{array}{c}34.587 \\
(31.281)\end{array}$ \\
\hline Population & $\begin{array}{c}140.524^{* *} \\
(66.908)\end{array}$ & $\begin{array}{c}85.914 \\
(64.166)\end{array}$ & $\begin{array}{r}111.335 \\
(80.377)\end{array}$ \\
\hline R-squared & 0.842 & 0.842 & 0.841 \\
\hline
\end{tabular}

Clustered standard error at municipality level in parentheses. $\quad \mathrm{N}=1,007 ;{ }^{*} \mathrm{p}<0.1 ;{ }^{* *} \mathrm{p}<0.05$; ${ }^{* * *} \mathrm{p}<0.01$. Control variables: value added for agriculture, manufacturing, services and government, number of firms and formal employment. Team, division, municipality and year fixed effects are included in all regressions. Elo score calculated with $k=10$ and initial ranking with point differential of 3 for each position. 
Appendix C2: Robustness Elo $3-k=30$ and point difference $=1$

\begin{tabular}{lccc}
\hline \hline & \multicolumn{3}{c}{ Dependent } \\
& Count & EGI & MSI \\
\hline \multirow{2}{*}{ Division A1 } & -3.487 & -2.301 & -4.152 \\
& $(11.298)$ & $(5.211)$ & $(16.748)$ \\
Division A2 & -1.142 & -1.094 & -0.674 \\
& $(4.138)$ & $(3.607)$ & $(8.078)$ \\
Division A3 & $6.203^{*}$ & $7.940^{* * *}$ & 3.709 \\
& $(3.236)$ & $(2.217)$ & $(3.373)$ \\
Division A4 & 4.801 & 1.830 & -3.598 \\
& $(5.796)$ & $(8.806)$ & $(19.498)$ \\
Median Wage & 36.895 & 39.335 & 39.688 \\
& $(31.620)$ & $(32.510)$ & $(32.521)$ \\
Population & $166.703^{* *}$ & 86.782 & 148.412 \\
& $(75.199)$ & $(69.138)$ & $(90.644)$ \\
R-squared & 0.697 & 0.698 & 0.697 \\
\hline \hline
\end{tabular}

Clustered standard error at municipality level in parentheses. $\quad \mathrm{N}=1,007 ;{ }^{*} \mathrm{p}<0.1 ;{ }^{* *} \mathrm{p}<0.05$; ${ }^{* * *} \mathrm{p}<0.01$. Control variables: value added for agriculture, manufacturing, services and government, number of firms and formal employment. Team, division, municipality and year fixed effects are included in all regressions. Elo score calculated with $k=30$ and initial ranking with point differential of 1 for each position. 
Appendix C3: Robustness Elo $4-k=10$ and point difference $=1$

\begin{tabular}{|c|c|c|c|}
\hline & \multicolumn{3}{|c|}{ Dependent variable: elo score 4} \\
\hline & Count & EGI & MSI \\
\hline Division A1 & $\begin{array}{c}-2.686 \\
(11.908)\end{array}$ & $\begin{array}{l}-2.897 \\
(5.271)\end{array}$ & $\begin{array}{c}-3.086 \\
(16.828)\end{array}$ \\
\hline Division A2 & $\begin{array}{l}-0.357 \\
(3.936)\end{array}$ & $\begin{array}{l}-0.444 \\
(3.193)\end{array}$ & $\begin{array}{c}0.981 \\
(7.686)\end{array}$ \\
\hline Division A3 & $\begin{array}{l}6.906^{* *} \\
(3.310)\end{array}$ & $\begin{array}{c}8.309^{* * *} \\
(2.305)\end{array}$ & $\begin{array}{c}4.468 \\
(3.268)\end{array}$ \\
\hline Division A4 & $\begin{array}{c}4.721 \\
(5.562)\end{array}$ & $\begin{array}{c}2.369 \\
(8.702)\end{array}$ & $\begin{array}{c}-3.685 \\
(19.056)\end{array}$ \\
\hline Median Wage & $\begin{array}{c}38.900 \\
(31.268)\end{array}$ & $\begin{array}{c}41.411 \\
(32.121)\end{array}$ & $\begin{array}{c}41.687 \\
(32.183)\end{array}$ \\
\hline Population & $\begin{array}{c}151.409^{* *} \\
(74.625)\end{array}$ & $\begin{array}{c}71.643 \\
(66.909)\end{array}$ & $\begin{array}{l}126.348 \\
(87.758)\end{array}$ \\
\hline R-squared & 0.700 & 0.700 & 0.699 \\
\hline
\end{tabular}

Clustered standard error at municipality level in parentheses. $\quad \mathrm{N}=1,007 ;{ }^{*} \mathrm{p}<0.1 ;{ }^{* *} \mathrm{p}<0.05$; ${ }^{* * *} \mathrm{p}<0.01$. Control variables: value added for agriculture, manufacturing, services and government, number of firms and formal employment. Team, division, municipality and year fixed effects are included in all regressions. Elo score calculated with $k=10$ and initial ranking with point differential of 1 for each position. 